\title{
THE EFFECTS OF TEAM - AND CUSTOMER-MEMBER EXCHANGE ON EMPLOYEE SERVCICE PERFORMANCE IN KOREAN HOTEL RESTAURANTS
}

\begin{abstract}
Mahn Hee Yoon
Abstract: This study focuses two exchange relationships at service workplace-team-member exchange (TMX), customer-member exchange (CMX) - that customer contact employees may be involved in during a service encounter. This study extends exchange relationships into the service marketing domain by investigating less explored exchanges but ones (CMX, TMX) that service employees typically engage in the service encounter. It also highlights the mediating role of team commitment in team-oriented work environment. Based on social exchange theory and the selfregulation of attitude, this study examines the effects of both exchange variables on an emotional/attitudinal response (team commitment) and behavior (service performance). Data were collected from 468 customer-contact employees across 21 restaurants in seven branches of a prominent hotel chain in South Korea. Structural equation modeling was used to evaluate proposed model and test hypotheses. The results showed that both TMX and CMX relationships have significant effect on team commitment, which in turn have positive impact on service performance. Team commitment mediated partially the positive relationships between both exchange variables and service performance. In regards to the direct effects on service performance, team commitment was strong relative to the effect of organizational commitment.

Future studies should incorporate customer ratings or immediate supervisors' ratings of subordinates to measure the employee service performance. Further, the customer-member exchange scale needs further investigation in other contexts, to insure we have adequately captured it. Service organizations should not limit the employee relationships only to the formal contract or economic exchanges. Service management should scrutinize the critical role of TMX and CMX as perceived by service employees in generating positive job-related attitudes (team commitment) and superior service performance.
\end{abstract}

Key words: team-member exchange, customer-member exchange, team commitment, service performance, hotel restaurant

\section{INTRODUCTION}

In hospitality businesses, service employees typically engage in multiple exchange relationships with a variety of individuals or groups inside or outside the organization. The exchanges employees have with the various parties, such as customers, coworkers, and immediate supervisors, strongly affect their job performance, making exchanges an important construct to examine in a service context. In the past few decades, organizational researchers have extensively studied the nature and role of employees' exchange relationships in organizations. Blau's (1964) social exchange theory provides a theoretical framework for understanding exchange relationships, noting that reciprocity-based exchanges are predictive of employees' positive work behaviors (e.g., extra-role behavior, low intention to quit) and attitudes (e.g., high job satisfaction and organizational commitment). Specifically, the leader-member exchange (hereafter referred to as LMX) (Liden et al.,, 2000) and perceived organizational support (hereafter referred to as POS) (Eisenberger et al., 1986) literatures show that employees' perceived quality of exchange

\footnotetext{
${ }^{1}$ Professor of Marketing, Department of Business Administration, Daegu University, Gyeongsan, Gyeongbuk, South Korea.
} 
with their organization and supervisors influence their performance and attitudes (Liden et al., 2000). In service management, both constructs have been often discussed in regards to internal marketing issues, where the internal exchange between the customer-contact employee and the organization must operate effectively and satisfactorily prior to the achievement of successful external exchanges.

Despite numerous exchange studies, still there can be several opportunities to extend exchange relationships into the services domain. We can expand on an existing type of exchange relationship not previously addressed enough in the service marketing literature-team-member exchange (hereafter referred to as TMX) (Seers, 1989). TMX is an important type of exchange relationship (Seers, 1989) in the management literature. Seers et al. (1995, p.22) define TMX as the degree to which an employee "incorporates his or her role in relation to the group...within the self concept." Despite its importance, researchers have not explored this exchange relationship relative to team commitment in the teamoriented workplaces. As Cole et al. (2002) argue, TMX is part of an employee's workplace social exchange network and, thus, is important to study. There is a growing recognition of the importance of the need to study work teams in their natural environments and their interrelationships to other types of exchange partners. Such integrative considerations help us understand the overall exchange dynamics in organizations that ultimately affect employee's decisions for behavioral or attitudinal reciprocation. In fact, some studies tried to explain team commitment in terms of perceived team support (Bishop et al., 2000), perceived task interdependence and intersender conflict (Bishop et al., 2000). But there was no attention paid to the relationship between team-member exchange and team commitment, even though both are key constructs in a team-oriented context.

In addition to TMX, there is another exchange that may strongly explain team commitment, which is customer-member exchange (hereafter referred to as CMX). This type of exchange relationship is particularly relevant in service encounters, where customers play important roles. Service employees, as boundary spanners, continuously interact with customers outside the organization, and their attitudes and service behaviors depend heavily on their perceptions of the quality of customer exchanges. Thus, customeremployee exchange is important to include as an exchange type in a service setting. Unlike other internal exchanges, it deals with the external exchanges between employees and customers and represents an employee's generalized perceptions (based on past customers and occasions) of his interactions with customers. Obviously, there are some studies in marketing that have explored constructs similar to this exchange relationship, such as commercial friendship (Price and Arnould, 1999) and customer-employee rapport (Gremler and Gwinner, 2000). However, the customer-employee exchange is different from these constructs in its theoretical base and its focus on the employee's perspective. Thus, it extends the ideas of leader- and team-member exchange into the services area, with a focus on employees' perceptions of the quality of their customer interactions.

In this paper, we attempt to examine the incremental contributions of TMX, CMX, and team commitment to explaining service employee's performance in a team-oriented service setting above the impact of LMX, POS, and organizational commitment on employee job performance (e.g., Liden et al., 1998). Specifically, following Bagozzi's (1992) self-regulation of attitudes (cognitive appraisal $\rightarrow$ attitudinal/emotional response $\rightarrow$ coping/behavior), this paper explores how two exchange relationships (TMX, CMX), as perceived by employees, influence their work attitude toward work team (team commitment), which in turn affects their behavior (service performance). 


\section{BACKGROUND AND HYPOTHESES}

\section{Team-member exchange (TMX)}

TMX refers to an employee's perception of his or her exchange relationship with the work group as a whole (Seers, 1989). Thus, it involves employees working together with other coworkers of the role set to accomplish their tasks. According to Seers et al. (1995), team members use the reciprocal behaviors inherent in a social exchange to reinforce individual roles.

As an individual level construct, TMX involves an employee's aggregation of role episode exchanges across members of their work group (Seers et al., 1995). Using a role theory perspective, TMX involves employees working together with other coworkers of their role set to accomplish their tasks. Likening it to team identification, Seers and his colleagues suggest that TMX involves the degree to which an employee "incorporates his or her role in relation to the group...within the self concept" (1995: 22) and entails generalized reciprocity (social exchange theory) of group members with one another and across the group such that greater team identification suggests higher TMX.

Employees who perceive low TMX, do not see themselves as strongly identifying with the team and therefore, the behaviors they enact as a result of that relationship involve the exchange of materials necessary for work completion. In contrast, those perceiving high TMX, see themselves as "team players," (Seers et al., 1995) and are more likely to engage in reciprocal exchanges of resources and social commodities, such as support, help, and recognition of team members, which go beyond the requirements of simple work execution (Liden et al., 2000). This concept relates also to the importance of positive connections in the workplace. As Dutton (2003: 7) states: "energy can be renewed and spread as individuals infect each other by connecting in positive ways."

\section{Customer-member exchange (CMX)}

CMX is an employee's generalized perception (across past customers and occasions) of his or her interactions with customers. It is an individual level construct and represents the employee's mental aggregation, reflecting his/her generalized feelings about all of his/her interactions with customers over time. Given the service encounter or relationship is a work environment, like climate perceptions, employees integrate their microperceptions of episodes or interactions with customers into macroperceptions of customer-exchange relationships (Diet et al., 2004). Also, following role theory, employees first look at what they bring to the relationship as well as that which is expected of them in their roles as employees. Then, as they encounter different customers, some level of exchange occurs with each customer and occasion (social exchange theory). The level of reciprocity will differ for each interaction but employees will be able to cognitively assess these relationships across all interactions, forming a generalized emotional response, e.g., "most of my interactions with customers are wonderful and make me feel good."

Thus, similar to LMX and TMX, low quality CMX involves pure exchange relationships with customers in accordance with job related requirements, while high quality interactions involve the exchange of social elements or commodities, such as mutual respect, trust, obligation, friendship and liking. These interactions may occur across different types of customer encounters or relationships. That is, employees may interact with customers they do not know and only interact with only once (i.e., encounters or pseudorelationships) or they may interact with regular customers, engaging in ongoing relationships (Gutek et al., 
1999). High-quality CMX exchanges are possible between employees and customers in both ongoing relationships and encounters.

CMX is a construct of employee-customer interaction and thus it is similar to the idea of rapport in the service literature, which involves "having an enjoyable interaction with a service provider employee, characterized by a personal connection between the two interactants" (Gremler and Gwinner, 2000: 92). However, Gremler and Gwinner emphasize this as a customer view, not really addressing it from the employee's perspective. CMX can also be similar to Dutton's (2003) notion of "high quality connections," composed of three elements--respectful engagement, task enabling, and trusting in the management literature. However, the concept of CMX is different from these ideas - its theoretical base is social exchange theory and it focuses on what is given and received by whom and for what reason (Cole al., 2002). Further, it is a logical extension of the relationship exchange partners already addressed in the management literature (leaders and team members). Finally, it encompasses a broad range of social content from the employee's (rather than the customer's perspective) - including mutual trust, professional respect, recognition or praise, and friendship and liking. The focus here is not on identifying the trait or personality aspects of this construct. Instead, the focus is on the degree to which employees would generally say that their customer exchanges involve positive feelings and energizing connections between themselves and their customers. This, in turn, would have many important consequences for employees, customers, and their firm.

\section{Exchange relationships and team commitment}

If service employees receive high-quality social currencies from their teammates in the forms of recognition, trust, and respect, then they will, in return be committed to the goals and values of their work team and be emotionally attached to the team and its members. As Seers et al. (1995) noted, employees use reciprocal attitudes inherent in a social exchange to reinforce individual roles and identify both within the group and for the group at large. Such reciprocal attitudes towards the team will be evident in the team-oriented work environment, where a work group or team is an immediate, local focus for employees. According to Lawler's (1992) theory of nested commitment, the immediate or local focus is more salient and has interaction advantage over distant foci. Thus, if the local focus has a positive effect on the working condition of service employees, they may attribute positive emotions to the local focus, which will be the object of their emotional attachment.

Just as service employees appreciate positive reactions and interactions from teammembers and supervisors, they also appreciate positive reactions and interactions with their customers (Bowen, 1983). When employees receive positive reactions from customers, they feel positive emotions towards their most immediate focus 'customers', and next to the most proximal individuals in the work environment- their teammates. Further, Lawler's (1992) nested commitment idea suggests that initially the customers and then the work team will become objects of the employee's emotional attachment. This may be a result of emotional contagion as well (Pugh, 2001). Thus, in a positive team-service environment, customers provide positive feedback that is transferred to positive feelings towards teammates, a sense of camaraderie and a mutuality of purpose in serving the customer, leading to the following hypotheses.

H1. Service employees' (a) team-member exchange and (b) customer-member exchange will be related positively to team commitment. 


\section{Team commitment and service performance}

Recent commitment literature indicates that employees' attitudinal commitment to the workplace is multidimensional and that the focus of commitment (that is, to whom or what employees are committed) is important in assessing employee attachment (Bishop et al., 2000). The team commitment of service employees is likely to influence their job performance positively because when employees feel emotionally attached to the team, they may be more willing to contribute to the work-team goals by increasing their personal performance. This is consistent with Fishbein and Ajzen's (1974) principle of compatibility that "a given attitude should be related to behavior only to the extent that the target (foci) of the attitude and behavior are similar" (Becker and Kernan, 2003, p.331). Thus, this involves a matching of commitment and performance foci.

$\mathrm{H} 2$. Team commitment will be positively related to employee service performance.

\section{Direct Effects of Exchanges on Employee Service Performance}

While only a few studies have examined the effects of team-member exchange on job performance, researchers have found that it influences job performance (Liden et al., 2000). In the Liden et al.'s study, the team-member exchange directly aided peers in attaining higher levels of performance, while emotional support and guidance from the immediate supervisor (LMX) did not. In regards to high-quality team-member exchange relationships, employees exchange work-related expertise or knowledge and/or feedback from teammates, which allows service employees to perform their jobs better. As Cole et al. (2002) argue, performance is an acceptable currency for social exchange.

Further, customers are also a source of positive feelings for service employees. Employees appreciate customers' rewarding, recognizing, and/or praising their behaviors as currencies for the customer-member exchange process. Like leader- and team-member exchanges, employees rely on customers for positive reactions (Bowen, 1983). Service employees may treat their customers differently in response to the quality of customer-member exchange. When high-quality exchange occurs, employees should reciprocate with more pleasant, rewarding behaviors towards customers, i.e., better job performance, although the empirical assessment of this linkage appears to have not been assessed. Thus, we offer the following.

H3. Service employees' (a) team member exchange and (b) customer-member exchange will be related positively to employee service performance.

\section{Mediation effect of team-commitment}

H4. Service employees' team commitment partially mediates the relationship between their (a) team member exchange and (b) customer-member exchange and service performance.

\section{DATA ANALYSIS AND RESULTS}

\section{Sample and data collection}

We surveyed approximately 700 service employees across 21 restaurants in seven branches of a luxury hotel chain in South Korea. A hotel restaurant is an appropriate setting for our empirical study because service employees in the restaurant services are subject to a variety of human interactions with both customers and internal parties - supervisors and team members. We received questionnaires from 468 employees (67\% response rate), 
excluding one employee response because of missing identification. The sample was $46 \%$ male and 54\% female. Seventy-six percent of the employees graduated junior college, $58 \%$ were less than 30 years old, and $65 \%$ not married. Twenty-eight percent of the sample had worked for the restaurant for less than one year, $42 \%$ one to three years, and $30 \%$ had worked there more than three years.

\section{Measurement model}

We estimated a confirmatory analysis (CFA) for validation for all of our measures including control variables, specifying a seven-construct measurement model with 49 item indicators. The CFA indicates a satisfactory fit of the data $\left(\chi^{2}=4807.77, \mathrm{df}=1106, \mathrm{p}<\right.$ .01 ; $\mathrm{TLI}=.95 ; \mathrm{CFI}=.95 ; \mathrm{RMSEA}=.08)$. All indicator loadings for constructs were high and significant $(\mathrm{p}<.01)$, with parameter estimates 15 to 24 times as large as the standard error. All scales achieved coefficient alphas and composite reliabilities greater than .87 and the proportions of variance extracted (AVEs) above the recommended level of .50, as shown in Table 1. Thus, our measures appear to have convergent validity.

Tab. 1. Summary statistics and internal consistency ${ }^{a}$

\begin{tabular}{llllllllll}
\hline $\begin{array}{l}\text { Me } \\
n\end{array}$ & SD & 1 & 2 & 3 & 4 & 5 & 6 & 7 \\
\hline
\end{tabular}

(Focal constructs)

$\begin{array}{lccccccc}\text { 1. Team-member exchange } & 5.08 & .93 & 00 & & & \\ \text { 2. Customer-member } & 5.14 & .86 & .50 & 1.00 & & \\ \text { exchange } & & & & & & \\ \text { 3. Team commitment } & 5.00 & 1.01 & .64 & .58 & 1.00 & \\ \text { 4. Service performance } & 5.21 & .93 & .56 & .58 & .67 & 0\end{array}$

\section{(Control variables)}

5. Perceived organization. support

$\begin{array}{llllllll}4.18 & 1.28 & .28 & .37 & .31 & .23 & 0\end{array}$

$6 . \quad$ Leader-member

exchange

$7 . \quad$ Organizational

$\begin{array}{llllllll}4.79 & .99 & .63 & .50 & .53 & .49 & .31 & 1.0\end{array}$

commitment

$\begin{array}{lllllllll}4.58 & 1.22 & .41 & .37 & .59 & .41 & .61 & .56 & 1.00\end{array}$

\begin{tabular}{llllllll}
\hline Internal Consistency & & & & & & & \\
\hline Cronbach's $\alpha$ & .93 & .88 & .89 & .88 & .95 & .88 & .93 \\
Composite Reliability & .92 & .87 & .91 & .89 & .95 & .89 & .95 \\
Average Variance Extracted & .54 & .54 & .60 & .56 & .73 & .57 & .73 \\
\hline
\end{tabular}

a. Correlation coefficients are disattenuated estimates from confirmatory factor analyses using LISREL.

Discriminant validity exists when the AVE values in each construct exceed the square of the coefficient $(\Phi)$ representing its correlation with other constructs (Fornell and Larcker, 1981). This criterion was satisfied across all pairs of constructs. See Table 1. Second, we calculated a two-standard error interval estimate of each coefficient $(\Phi)$ to examine whether the correlation coefficient plus two standard errors included the value 1.0. None of 
the 95 percent confidence intervals for any correlation did. Thus, discriminant validity appears to exist between all pairs of constructs.

\section{Structural Model Results}

We simultaneously estimated the hypothesized paths among focal constructs and the paths among the focal constructs and control variables. Netemeyer and his colleagues (2005: 137) suggest that " the recent trend in structural equation models is to control for variables that are not central to study hypotheses." Thus we also estimated paths among control variables and their linkages to service performance. This full structural model fits the data well $\left(\chi^{2}=4890.03, \mathrm{df}=1111, \mathrm{p}<.01 ; \mathrm{TLI}=.94 ; \mathrm{CFI}=.95 ; \mathrm{RMSEA}=.08\right)$. Table 2 presents the standardized estimates for structural paths in the proposed model. All hypothesized relationships were supported at $\mathrm{p}<.05$ or better. As predicted in H1a and $\mathrm{H} 1 \mathrm{~b}$, team commitment was positively impacted by team-member exchange $(\gamma=.47, \mathrm{t}=$ 9.35) and customer-member exchange $(\gamma=.36, \mathrm{t}=7.35)$. Both exchange paths explained $51 \%$ of the variance in team commitment. We also predicted that service employees' team commitment would affect their service performance. Supporting H2, team commitment positively influenced employees' service performance $(\beta=.39, \mathrm{t}=6.24)$. In H3a and H3b, we predicted that both team- and customer-member exchanges would directly influence service performance. Both paths were supported (team-member exchange: $\gamma=.14, \mathrm{t}=$ 2.20; customer-member exchange: $\gamma=.26, \mathrm{t}=4.51$ ).

Tab. 2. Structural model estimation results

\begin{tabular}{|c|c|c|}
\hline Structural paths & Coefficient & t-value \\
\hline \multicolumn{3}{|l|}{ (Hypothesized Paths) } \\
\hline TMX $\rightarrow$ Team commitment (H1a) & .47 & $9.35 * * *$ \\
\hline $\mathrm{CMX} \rightarrow$ Team commitment (H1b) & .36 & $7.35^{* * *}$ \\
\hline Team commitment $\rightarrow$ Service performance (H2) & .39 & $6.24 * * *$ \\
\hline TMX $\rightarrow$ Service performance (H3a) & .14 & $2.20 * * *$ \\
\hline $\mathrm{CMX} \rightarrow$ Service performance (H3b) & .26 & $4.51 * * *$ \\
\hline \multicolumn{3}{|l|}{ (Control variable paths) } \\
\hline POS $\rightarrow$ Organizational commitment & .49 & $11.64 * * *$ \\
\hline LMX $\rightarrow$ Organizational commitment & .41 & $9.95 * * *$ \\
\hline $\mathrm{POS} \rightarrow$ Service performance & -.07 & $-1.37 * * *$ \\
\hline LMX $\rightarrow$ Service performance & .08 & $1.21 * * *$ \\
\hline $\begin{array}{l}\text { Organizational commitment } \rightarrow \text { Service } \\
\text { performance }\end{array}$ & .04 & $.69^{* * *}$ \\
\hline
\end{tabular}

Model Fit: $\chi^{2}=4890.03$, d.f. $=1111, \mathrm{p}<.01 ;$ TLI $=.94$, CFI $=.95$, RMSEA $=.088$ $*<.10 * *<.05 * * *<.01$ 
In order to assess empirically the mediation role of team commitment in the effects of two exchange variables to service performance (H4), we compared the hypothesized partial mediation model with the fully mediated model. The chi-square difference $\left(\Delta \chi^{2}\right)$ test was used to compare the two models. The result $\left(\Delta \chi^{2}=25.22\right.$ with $\left.\Delta \mathrm{df}=2, \mathrm{p}<.01\right)$ shows that the partially mediated model is better-fitting than the fully mediated model. Using another SEM approach to assess mediation (Schneider et al., 2005; MacKinnon et al., 2002), we found that the team commitment played a partial mediator role between both exchange variables and service performance. Partial mediations exist if the direct path (TMX or $\mathrm{CMX} \rightarrow$ service performance) remains significant (TMX: $\gamma=.14, \mathrm{t}=2.20$; CMX: $\gamma=.26, \mathrm{t}$ $=4.51$ ), while paths (a) and (b) (TMX or CMX $\rightarrow$ team commitment; team commitment $\rightarrow$ service performance) are significant (TMX: $\gamma=.47, \mathrm{t}=9.35$; CMX: $\gamma=.36, \mathrm{t}$ $=7.35$; and $\beta=.39, \mathrm{t}=6.24$, respectively).

\section{CONCLUSIONS}

As anticipated, we found evidence that recognition or supportive behaviors from workteams and customers can affect service employees' emotional attachment to their team. Even though not explored in previous studies, this result indicates that the social exchange theory can provide a theoretical base for understanding the influences of TMX and CMX on team commitment, and provides an empirical answer to prior findings in organizational studies that argue for the further development of exchange relationship types.

Further, we found that employees' emotional attachment to their team is an important attitudinal antecedent of their service performance. This finding underscores the importance of matching the form of commitment to type of performance, consistent with Fishbein and Ajzen's (1974) principle of compatibility. Also, we find that service employees who feel attached to the work team are more willing to contribute to their team by engaging in higher quality service. This indicates that service performance has foci as well. Field theory (Lewin 1943) also provides a rationale for this result. Team commitment contributes more to work performance than organizational commitment due to the greater physical proximity of teammates and their psychological saliency to the one another.

Our results indicate that when employees receive positive social exchange currencies from team members and customers they perform better. These findings suggest that researchers should pay more attention to understanding the effects of TMX and CMX on employees' service performance. The powerful effect of CMX on service behaviors cannot be overemphasized. It implies that the positive feedback or emotional support that employees receive from customers is a strong motivator, which contributes in an important way to excellent service behaviors. When service employees perceive customers' rewarding, recognizing, and/or praising their behaviors as currencies for high-quality exchange, the norm of reciprocity (Gouldner, 1960) sets in, such that they reciprocate with more pleasant or better service performance as positive behavioral currencies.

\section{REFERENCES}

Bagozzi, R.P. (1992). The self-regulation of attitudes, intentions, and behavior. Social Psychology Quarterly, Vol. 55, 178-204. 
Becker T.E. and Kernan, M.C. (2003). Matching commitment to supervisors and organization to in-role and extra-role performance. Human Performance, Vol. 16 No.4, 327-348.

Bishop, J. and Scott, K. (2000). An examination of organizational and team commitment in a self-directed team environment. Journal of Applied Psychology, Vol.85 No.3, 439450.

Blau, P. (1964). Exchange and power in social Life, Wiley, New York, NY.

Bowen, D.E. (1983). Customers as substitutes for leadership, doctoral dissertation, Michigan State University, East Lansing, MI.

Cole M.S., Schaninger W.S. and Harris, S.G. (2002). The workplace social exchange network: a multilevel, conceptual examination. Group \& Organizational Management. Vol. 27 No.1,142-167.

Dutton, J.E. (2003). Energize your workforce: how to build and sustain high-quality connections at work. Jossey-Bass Publishers, San Francisco, CA.

Eisenberger R., Hungtington R., Hutchison S. and Sowa, D. (1986). Perceived organizational support. Journal of Applied Psychology, Vol. 71 No.3, 500-507.

Fishbein, M. and Ajzen, I. (1974). Attitudes toward objects as predictors of single and multiple behavioral criteria. Psychological Review, Vol. 81, 59-74.

Fornell, C. and Larcker, D. F. (1981). Evaluating structural models with unobservable variables and measurement error. Journal of Marketing Research, 18, 39-50.

Gouldner, A.W. (1960). The norm of reciprocity: a preliminary statement. American Sociological Review, Vol. 25, 165-167.

Gremler, D.D. and Gwinner, K.P. (2000).Customer-employee rapport in service relationships. Journal of Service Research, Vol. 3 No. 1, 82-104.

Gutek, B., Bhappu ,A., Liao-Troth M. and Cherry, B. (1999). Distinguishing between service relationships and encounters. Journal of Applied Psychology, Vol. 84 No.2, 218-233.

Lawler, E.J. (1992). Affective attachment to nested groups, American Sociological Review, Vol.57, 327-339.

Lewin, K. (1943). Defining the field at a given time. Psychological Review, Vol. 50, 292310.

Liden, R.C., Wayne, S.J. and Sparrowe, R.T. (2000). An examination of the mediating role of psychological empowerment on the relations between the job, interpersonal relationships, and work outcomes. Journal of Applied Psychology, Vol.85 No. 3, $407-$ 416.

Netemeyer, R.G., Maxham J.G. and Pullig, C. (2005). Conflicts in the work-family interface: links to job stress, customer service employee performance, and customer purchase intent. Journal of Marketing, Vol. 69, 130-143.

Price, L. and Arnould, E. (1999). Commercial friendships: service provider-client relationships in context. Journal of Marketing, Vol. 63 No. 4, 38-56.

Pugh, S.D. (2001). Service with a smile: emotional contagion in the service encounter. Academy of Management Journal, Vol. 44 No.5, 1018-1027.

Seers, A. (1989). Team-member exchange quality: a new construct for role-making research. Organizational Behavior and Human Decision Processes, Vol. 43 No.1, 118-135.

Seers, A., Petty, M.M. and Cashman, J.F. (1995). Team-member exchange under team and traditional management: a naturally occurring quasi-experiment. Group and Organizational Management, Vol. 20, 18-38. 